Section Editor

Robert C. Griggs, MD
Editors' Note: In response to Dr. Sabour's and Dr. Morrow's comments on the reliability and accuracy of skeletal muscle imaging in limb-girdle muscular dystrophies, Drs. ten Dam et al. respond and provide 2 additional tables summarizing the positive and negative likelihood ratios as well as test characteristics of uninformative scans. These important additional data were not included in the original publication because of space constraints.

Chafic Karam, MD, and Robert C. Griggs, MD

\section{RELIABILITY AND ACCURACY OF SKELETAL MUSCLE IMAGING IN LIMB-GIRDLE MUSCULAR DYSTROPHIES}

Siamak Sabour, Tehran, Iran: ten Dam et al. evaluated the reliability and accuracy of skeletal muscle CT to correctly identify different muscular dystrophies manifesting with limb-girdle weakness. ${ }^{1}$ They reported that the overall interobserver agreement was poor (kappa $=0.27$ ), with markedly higher scores for Becker muscular dystrophy (BMD) (kappa $=0.51)$ and Bethlem myopathy (kappa $=0.59)$. For reliability analysis for qualitative variables, weighted kappa should be used with caution because kappa has its own limitations. ${ }^{2-5}$ They also reported that sensitivity was $40 \%$, specificity $58 \%$, positive predictive value $77 \%$, and negative predictive value $21 \%$. These results do not reflect acceptable validity. The authors should have used positive and negative likelihood ratio $(\mathrm{LR}+$ and $\mathrm{LR}-$ ) as well as odds ratio (OR) (true/false) to completely evaluate validity or diagnostic accuracy. ${ }^{2-5}$ As the authors concluded, muscle CT might be an adjunct to the clinical diagnosis of BMD and Bethlem myopathy. This conclusion may be misleading due to inappropriate or incomplete use of the relevant validity and reliability analysis.

Author Response: Leroy ten Dam, Anneke J. van der Kooi, Menno van Wattingen, Rob J. de Haan, Marianne de Visser, Amsterdam: The authors thank Dr. Sabour for his comments. We did not use weighted kappa to investigate the interrater agreement because the multiple diagnostic scoring categories studied are not ordinal. We also studied more than 2 observers so we used Fleiss generalized kappa (see Methods ${ }^{1}$ ) as a measure of overall concordance of multiple raters using nominal scoring
WriteClick: Editor's Choice

categories. ${ }^{6}$ We are aware that this unweighted kappa approach gives a conservative estimate of the interobserver agreement due to the multiple scoring categories and have stressed this disadvantage in the Discussion.

We did calculate the LR+ and LR - and the OR, but did not present this data in the article due to space limitations. We now supply the LR + LR- and diagnostic OR as additional information (table 1). The LR+ and diagnostic OR are markedly higher and $\mathrm{LR}-$ is markedly lower in BMD and Bethlem myopathy compared to the other groups, which supports our conclusion that muscle CT might be an adjunct to the clinical diagnosis of BMD and Bethlem myopathy, but not for the other limb-girdle muscular dystrophies. However, we still believe that the reliability is too low for individual clinical decisionmaking and therefore skeletal muscle imaging is insufficient for use in clinical practice.

(C) 2013 American Academy of Neurology

1. Ten Dam L, van der Kooi AJ, van Wattingen M, de Haan RJ, de Visser M. Reliability and accuracy of skeletal muscle imaging in limb-girdle muscular dystrophies. Neurology 2012;79:1716-1723.

2. Jeckel JF, Katz DL, Elmore JG, Wild DMG. Epidemiology, Biostatistics and Preventive Medicine, 3rd ed. Philadelphia: Saunders Elsevier; 2007.

\begin{tabular}{|llll|}
\hline Table 1 & \multicolumn{3}{l|}{$\begin{array}{l}\text { Positive and negative likelihood ratio } \\
\text { and diagnostic odds ratio }\end{array}$} \\
\hline Category & LR+ & LR- & Odds ratio \\
Overall & 0.95 & 1.04 & 0.92 \\
BMD & 7.22 & 0.10 & 72.55 \\
LGMD2C-F & 2.81 & 0.84 & 3.32 \\
\hline LGMD2I & 0 & 0 & 0 \\
\hline LGMD1B & 1.28 & 0.99 & 1.29 \\
\hline LGMD2A & 2.11 & 0.96 & 2.19 \\
\hline Bethlem myopathy & 22.5 & 0.10 & 216 \\
LGMD2L & 0 & 1.03 & 0 \\
\hline Miscellaneous & 2.79 & 0.53 & 5.29 \\
\hline
\end{tabular}

Abbreviations: BMD = Becker muscular dystrophy; LGMD = limb-girdle muscular dystrophy; LR+ = the proportion of sensitivity/1 - specificity; LR- = the proportion of $(1-$ sensitivity)/specificity; odds ratio $=$ the proportion of $(\mathrm{LR}+/ \mathrm{LR}-)$. 
3. Rothman JK, Greenland S, Lash TL. Modern Epidemiology, 3rd ed. Baltimore: Lippincott Williams \& Wilkins; 2008.

4. Szklo M, Nieto FJ. Epidemiology; Beyond the Basics, 2nd ed. New York: Jones and Bartlett; 2007.

5. Bland JM, Altman DG. Agreed statistics: measurement method comparison. Anesthesiology 2012;116:182-185.

6. Fleiss JL. Measuring nominal scale agreement among many raters. Psychol Bull 1971;76:378-382.

Jasper M. Morrow, Mary M. Reilly, Michael G. Hanna, London: The authors' analysis of using pattern on imaging in isolation to diagnose subtypes of LGMD $^{1}$ highlights the lack of strong data in this area. The overview of the pattern of muscle involvement in LGMD is a fair summary of the available literature. However, the patterns described for LGMD2I, LGMD1B, LGMD2A, and LGMD2L are very similar, with overall posterior greater than anterior thigh involvement and predominant medial gastrocnemius and soleus involvement in the calf. It is therefore not surprising that both interobserver agreement and sensitivity/specificity for these diagnoses are low. Conversely, the patterns described for Bethlem and Becker are more distinctive, accounting for the higher reliability and sensitivity for these diagnoses.

The exclusion of uninformative scans because they revealed too little or too much pathology is not reflective of real-world usage. The authors outline this in the Discussion but could have provided analysis with these scans included. While the role of imaging in congenital myopathies with rigidity of the spine is well known, ${ }^{2}$ systematic analysis of a greater number of patients is needed to assess if any imaging features are useful in distinguishing subtypes of LGMD.

Author Response: Leroy ten Dam, Anneke J. van der Kooi, Menno van Wattingen, Rob J. de Haan, Marianne de Visser, Amsterdam: We agree with Morrow et al. that more data are needed on patterns of muscle involvement in the subtypes of LGMD. In our Discussion, ${ }^{1}$ we noted that most studies in which these patterns are described include relatively small cohorts, ranging from 7 LGMD2L $\mathrm{L}^{3}$ and LGMD2A patients ${ }^{4}$ to 22 laminopathy patients. ${ }^{5}$

The patterns described for LGMD1B, LGMD2A, LGMD2I, and LGMD2L are similar, which contributes to the disappointing test characteristics found in these groups. However, the more distinctive pattern of muscle involvement found in the sarcoglycanopathies (LGMD2C-F) group did not result in higher test characteristics, suggesting that there are more factors responsible for the low test characteristics.

We excluded uninformative scans to calculate the accuracy of muscle imaging in LGMDs under optimal conditions. As stated in our Discussion, we agree 
that this does not reflect clinical practice and therefore, as suggested by Morrow et al., we have provided the test characteristics that include uninformative scans (table 2). The test characteristics of BMD and Bethlem myopathy are still markedly better compared with the other LGMDs. When calculating the reliability of muscle imaging, no scans were excluded.

(C) 2013 American Academy of Neurology

1. ten Dam L, van der Kooi AJ, van Wattingen M, de Haan RJ, de Visser M. Reliability and accuracy of skeletal muscle imaging in limb-girdle muscular dystrophies. Neurology 2012;79:1716-1723.
2. Mercuri E, Clements E, Offiah A, et al. Muscle magnetic resonance imaging involvement in muscular dystrophies with rigidity of the spine. Ann Neurol 2010;67:201-208.

3. Hicks D, Sarkozy A, Muelas N, et al. A founder mutation in Anoctamin 5 is a major cause of limb-girdle muscular dystrophy. Brain 2011;134:171-182.

4. Mercuri E, Bushby K, Ricci E, et al. Muscle MRI findings in patients with limb girdle muscular dystrophy with calpain 3 deficiency (LGMD2A) and early contractures. Neuromuscul Disord 2005;15:164-171.

5. Carboni N, Mura M, Marrosu G, et al. Muscle imaging analogies in a cohort of patients with different clinical phenotypes caused by LMNA gene mutations. Muscle Nerve 2010;41:458-463.

\section{CORRECTION}

Vision assessment using the NIH Toolbox

In the article "Vision assessment using the NIH Toolbox" by R. Varma et al. (Neurology 2013;80:S37-S40), there is an error in the references. The author in reference 12 should read Hays R. The authors regret the error. 


\section{Neurology}

\section{Reliability and accuracy of skeletal muscle imaging in limb-girdle muscular dystrophies}

Siamak Sabour, Leroy ten Dam, Jasper M. Morrow, et al.

Neurology 2013;80;2275-2277

DOI 10.1212/WNL.0b013e318299ef6b

This information is current as of June 10, 2013

Updated Information \& Services

References

Permissions \& Licensing

Reprints including high resolution figures, can be found at: http://n.neurology.org/content/80/24/2275.full

This article cites 8 articles, 2 of which you can access for free at: http://n.neurology.org/content/80/24/2275.full\#ref-list-1

Information about reproducing this article in parts (figures,tables) or in its entirety can be found online at:

http://www.neurology.org/about/about_the_journal\#permissions

Information about ordering reprints can be found online:

http://n.neurology.org/subscribers/advertise

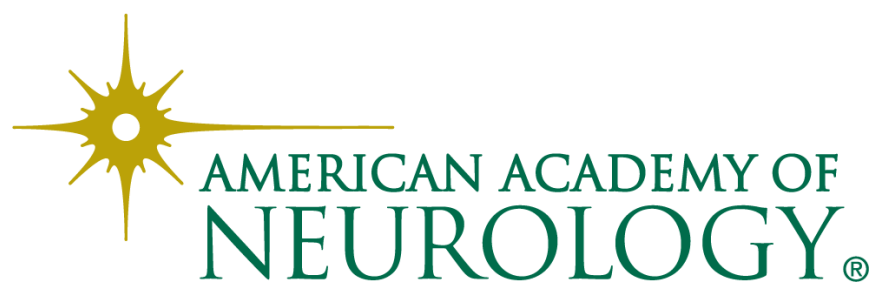

